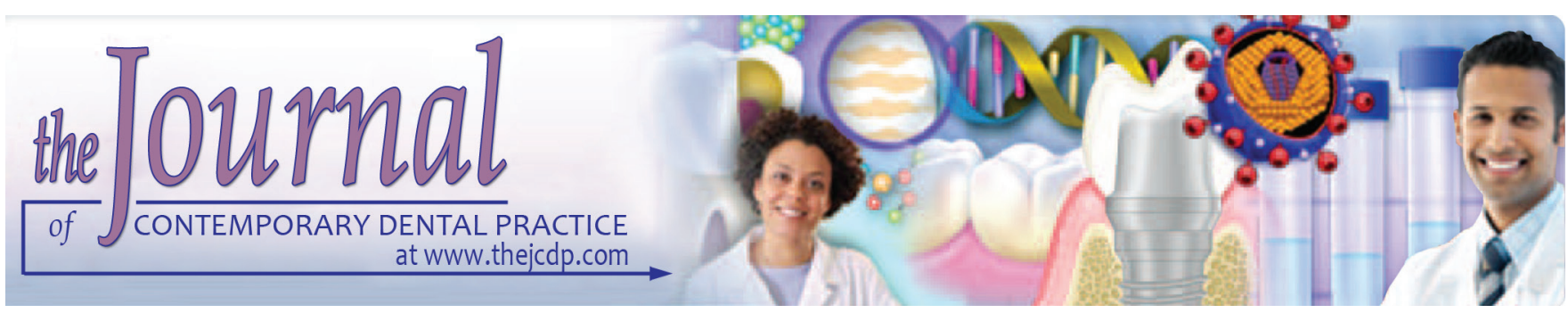

\title{
General Dental Practitioners as Potential Responders to Disaster Scenario in a Highly Disaster-prone Area: An Explorative Study
}

${ }_{1}^{1}$ Gururaghavendran Rajesh, ${ }^{2}$ Almas Binnal, ${ }^{3}$ Mithun BH Pai, ${ }^{4}$ Vijayendranath Nayak, ${ }^{5}$ Ramya Shenoy, ${ }^{6}$ Ashwini Rao

\begin{abstract}
Aim: The aim of this study is to obtain insights pertaining to disaster management among Indian general dental practitioners (GDPs).

Materials and methods: All GDPs in Mangaluru city, Karnataka, India, were included in the present study. Their willingness to participate in disaster management and their objective knowledge, attitude, behavior, and perceived effectiveness related to disaster management were assessed by a structured, pretested, self-administered questionnaire. Demographic information was also collected.
\end{abstract}

Results: Overall, 101 GDPs volunteered for the study, and $96.04 \%$ of respondents were willing to participate in disaster management. Mean knowledge, attitude, behavior, and perceived effectiveness scores were $52.65,79.60,41.55$, and $64.20 \%$ respectively. Religion (odds ratio $[\mathrm{OR}]=-0.194, \mathrm{p}=$ $0.022)$, marital status ( $O R=-0.222, p=0.040)$, attachment to college $(O R=-0.256, p=0.037)$, familiarity with standard operating procedures (SOP; OR $=-0.502, p=0.000$ ), and knowledge $(O R=0.265, p=0.003)$ were significant predictors of behavior.

Conclusion: The GDPs reported knowledge and behavior scores which were low, while their attitude and willingness to participate were high. Demographic determinants might be critical indicators in disaster management scenario among GDPs.

Clinical significance: The present study has crucial implications for policymakers and curriculum changes to integrate dentists effectively into disaster response teams. As responsible

\footnotetext{
1,3-6 Department of Public Health Dentistry, Manipal College of Dental Sciences, Manipal University, Mangaluru, Karnataka India

${ }^{2}$ Department of Oral Medicine and Radiology, Manipal College of Dental Sciences, Manipal University, Mangaluru, Karnataka India

Corresponding Author: Almas Binnal, Department of Oral Medicine and Radiology, Manipal College of Dental Sciences Manipal University, Mangaluru, Karnataka, India, Phone: +918242445858, e-mail:dr_almas123@yahoo.co.in
}

members of the society, the dental fraternity has critical contributions to make toward disaster mitigation. Integration of GDPs in a multidisciplinary team managing disasters might be crucial, especially in highly disaster-prone areas, such as India, with a definite paucity of resources.

Keywords: Dentists, Disaster management, Health care delivery system, Policy implications, Survey.

How to cite this article: Rajesh $G$, Binnal $A, P a i \quad M B H$, Nayak V, Shenoy R, Rao A. General Dental Practitioners as Potential Responders to Disaster Scenario in a Highly Disasterprone Area: An Explorative Study. J Contemp Dent Pract 2017;18(12):1144-1152.

Source of support: Nil

Conflict of interest: None

\section{INTRODUCTION}

The word "disaster" has been derived from the words "dis" meaning bad and "aster" meaning "stars". ${ }^{1}$ Disaster, hence, implies the effects of the bad influence of stars. More recently, disaster is identified as any particular event or a situation that "overwhelms local capacity, necessitating a request to a national or international level for external assistance" ${ }^{2}$. With the frequency of disasters becoming alarmingly high, they have emerged as a threat to global health in recent times.

Disasters that disrupt the health and welfare of communities may be natural or artificial. ${ }^{3}$ Earthquakes, torrents, cyclones, tornadoes, and droughts are natural disasters, whereas events, such as armed combats, military emergencies, and acts of terror employing "chemical, biological, radiological, nuclear, and explosive devices $(\mathrm{CBRNE})^{\prime \prime 4}$ are disasters that can be classified as artificial. These disasters can have a wide-ranging effect on communities., ${ }^{3,7}$ They lead to injuries and fatalities, destruction of public and personal property, displacement 
of populations, and emotional bereavement. Ultimately, they affect the progressive development of an entire nation and may, in fact, push back the progress of the nation by several decades. ${ }^{8}$ Becker $^{9}$ and Bhave et $\mathrm{al}^{10}$ have observed that the most severe consequences of disasters can be observed in developing countries with large populations affected by poverty.

Trained workforce who can contribute effectively to the management of disasters is one of the crucial aspects of disaster management. Due to the ensuing shortage of trained workforce that one can observe immediately after a disaster, this particular situation has been termed as "surge environment". ${ }^{5,11}$ Conventionally, only medical personnel are pressed into duty in the aftermath of a disaster. Other health professionals may have important contributions to make toward mitigation of disasters, thereby bridging the gap created by a shortage of conventional medical personnel. ${ }^{4,5}$ It has been observed that dentists may contribute efficiently and meaningfully to disaster management with minimal additional training.

Initially, dentists aided in mitigation of disasters by virtue of their expertise in forensic odontology and as members of military and "Disaster Mortuary Operational Response Teams"..${ }^{12-16}$ Dentists possess various important skills that can be of significant contribution during the times of disasters, and the scientific literature is replete with documented instances highlighting the part played by dentists during the trying times of disasters. ${ }^{4,17-22}$ As they are considered by the general public to be respected members of the society, ${ }^{23}$ they are entrusted with the responsibility of protecting the public. On ethical grounds, they are expected to work toward the betterment of the population.

Chhabra et $\mathrm{al}^{24}$ have reported that Indian dentists in Rajasthan might constitute an ignored pool of personnel during disasters. Mangaluru city is a major port in Karnataka state located on India's western coastline between the Arabian Sea and the Western Ghats. It has also been reported that India is one of the many countries which are prone for disasters. ${ }^{25-27}$ The report on disaster scenario in India published by the Government of India in the year 2004 indicated that a total of 75.84\% of India's coastline is susceptible to cyclones and tsunami. ${ }^{28}$ The proximity of Mangaluru to the Western Ghats makes it vulnerable to the threats of landslides and probably to earthquakes. One also needs to consider the constant threat of CBRNE-related disasters. All these aspects render Mangaluru a highly disaster-prone city in India. Thus, there is a definite need to identify crucial areas pertaining to managing disasters in Mangaluru.

A number of students enrolling to dental institutions have increased significantly in recent times. ${ }^{29}$ Earlier investigators have reported disaster management issues among Indian dental students. ${ }^{30,31}$ As a consequence of increased enrollment to dental training, there has been an increase in the number of GDPs in India. Since they have established their practices in various parts of the country, GDPs have the distinct feature of having significant access to the community. This confers a crucial advantage to them, as it enables them to render timely and effective services during public health emergencies. This is, especially, of great relevance in developing nations, such as India, which are highly disaster-prone but have limited resources at its disposal. This research work is the first exploration pertaining to disaster management among Indian GDPs in a highly disaster-prone region.

\section{MATERIALS AND METHODS}

The GDPs in Mangaluru city, located in the Indian state of Karnataka, were the study subjects. Ethical clearance was obtained from the Institutional Ethics Committee, Manipal College of Dental Sciences, Manipal University, Mangaluru, India. The purpose of the study was explained to the GDPs, and they were invited to participate in the present research work.

A questionnaire was used to explore various issues pertaining to the management of disasters among the respondents. ${ }^{30,31}$ This questionnaire explored the participants' willingness to participate in disaster management, objective knowledge, attitude, and behavior related to management of disasters. The questionnaire also explored their perceived effectiveness and any prior training related to management of disasters. Items for the instrument employed in the present study were obtained from earlier research, relevant theoretical background, views of experts, and investigators' reflection. ${ }^{30-32} \mathrm{~A}$ total of 26 items were employed to assess knowledge: 8 questions assessed attitude and behavior and 3 items were used to assess perceived effectiveness. Responses of "definitely yes", "yes", "neutral", "no", and "definitely no" on a 5-point Likert scale were used to assess attitude and perceived effectiveness. Behavior was assessed by response options $<1$ month, 1 to 6 months, 6 to 12 months, $>1$ year, and never.

Items assessing knowledge included common disasters, identification of victims, and bioterrorism. Questions that explored the need for dentists in the management of disasters, should they synchronize their work with other personnel in disaster management, should they keep abreast with recent advancements in disaster management, and need for record maintenance to aid in the identification of individuals were employed to assess the attitude of respondents. How frequently the respondents read about disaster management from journals and the Internet, record maintenance, and attending programs 
which trained them in disaster management assessed the behavior of participants. Questions regarding whether the study subjects felt that they can act efficiently during times of disasters and whether they can recognize bioterrorism and its signs and symptoms in the oral cavity assessed perceived effectiveness.

Knowledge was assessed on a scale from 0 to 26, attitude and behavior were assessed on a scale from 8 to 40 each, and perceived effectiveness was assessed on a scale from 3 to 15. Appropriate responses for knowledge were marked as " 1 ", attitude and perceived effectiveness were marked on a scale from 1 to 5 , ranging from definitely no to definitely yes, and behavior was marked from 1 to 5 , ranging from never to $<1$ month. Pilot testing of the instrument was conducted before the main study. Final data collection was done from December 2015 to May 2016.

The MS Office Excel was employed for entering the data, and Statistical Package for the Social Sciences version 16.0 was employed for statistical analysis. Intergroup analysis for various parameters among age, gender, religion, marital status, qualification, years of practice, and attachment to college of the study subjects was assessed by employing Student's t-test. Correlation among different variables in the present study was performed by Pearson's coefficient. Multiple linear regression analysis was employed to explore predictors for various variables related to disaster management. Level of significance for the present study was fixed at $5 \%$.

\section{RESULTS}

Cronbach's alpha and split-half reliability values for knowledge were found to be 0.72 and 0.86 and those for attitude was 0.88 and 0.85 respectively. Items for behavior had Cronbach's alpha and split-half reliability values of 0.88 and 0.87 , whereas for perceived effectiveness, it was found to be 0.78 and 0.83 respectively. All the GDPs in Mangaluru were invited to participate. A total of 120 GDPs were approached and invited to participate in the study. Overall, 101 respondents returned the questionnaire, representing a response rate of $84.17 \%$. The average age of the respondents was 34.11 years, with a majority of $53(52.48 \%)$ being males and $48(47.52 \%)$ being females. A total of 76 respondents were Hindus (75.25\%), whereas $25(24.75 \%)$ respondents were of other faith. Overall, a majority of 75 study subjects $(74.26 \%)$ were married, 63 of them $(62.38 \%)$ had completed their postgraduation, and 76 respondents $(75.25 \%)$ were attached to a dental institution. A majority of the 76 respondents $(75.25 \%)$ had established their private practice $\leq 10$ years ago (Table 1 ). Overall, the average knowledge, attitude, behavior, and perceived effectiveness scores of the study subjects were $13.69 \pm 4.21,31.84 \pm 5.00,16.62 \pm 7.76$, and $9.63 \pm 2.51$ respectively (Table 1$)$.

Table 1: Demographic variables and knowledge, attitude, and behavior about disaster management among study subjects

\begin{tabular}{|c|c|c|c|c|c|}
\hline Demographic variable & $n(\%)$ & $\begin{array}{l}\text { Knowledge } \\
(\text { Mean } \pm S D)\end{array}$ & $\begin{array}{l}\text { Attitude } \\
(\text { Mean } \pm S D)\end{array}$ & $\begin{array}{l}\text { Behavior } \\
(\text { Mean } \pm S D)\end{array}$ & $\begin{array}{l}\text { Perceived effectiveness } \\
(\text { Mean } \pm S D)\end{array}$ \\
\hline \multicolumn{6}{|l|}{ Age (years) } \\
\hline $21-25$ & $68(67.33)$ & $13.31 \pm 4.334$ & $31.32 \pm 5.199$ & $16.69 \pm 7.802$ & $9.49 \pm 2.403$ \\
\hline $25-30$ & $33(32.67)$ & $14.48 \pm 3.898$ & $32.91 \pm 4.454$ & $16.48 \pm 7.775$ & $9.94 \pm 2.715$ \\
\hline \multicolumn{6}{|l|}{ Gender } \\
\hline Male & $53(52.48)$ & $13.87 \pm 4.306$ & $32.15 \pm 5.419$ & $15.92 \pm 7.529$ & $9.40 \pm 2.803$ \\
\hline Female & $48(47.52)$ & $13.50 \pm 4.146$ & $31.50 \pm 4.529$ & $17.40 \pm 8.005$ & $9.90 \pm 2.126$ \\
\hline \multicolumn{6}{|l|}{ Religion } \\
\hline Hindu & $76(75.25)$ & $13.93 \pm 4.206$ & $32.42^{\star} \pm 4.748$ & $17.17 \pm 7.861$ & $0.902 \pm 2.376$ \\
\hline Others & $25(24.75)$ & $12.96 \pm 4.238$ & $30.08^{*} \pm 5.431$ & $14.96 \pm 7.323$ & $1.465 \pm 2.806$ \\
\hline \multicolumn{6}{|l|}{ Marital status } \\
\hline Single & $26(25.74)$ & $14.46 \pm 3.420$ & $31.04 \pm 4.582$ & $18.08 \pm 6.916$ & $9.50 \pm 1.817$ \\
\hline Married & $75(74.26)$ & $13.43 \pm 4.445$ & $32.12 \pm 5.139$ & $16.12 \pm 8.007$ & $9.68 \pm 2.712$ \\
\hline \multicolumn{6}{|l|}{ Qualification } \\
\hline BDS & $38(37.62)$ & $13.95 \pm 3.377$ & $31.03 \pm 4.284$ & $15.71 \pm 6.742$ & $9.32 \pm 2.182$ \\
\hline MDS & $63(62.38)$ & $13.54 \pm 4.666$ & $32.33 \pm 5.361$ & $17.17 \pm 8.310$ & $9.83 \pm 2.679$ \\
\hline \multicolumn{6}{|l|}{ Years of practice } \\
\hline$\leq 10$ & $76(75.25)$ & $13.59 \pm 3.882$ & $31.53 \pm 4.550$ & $16.36 \pm 7.671$ & $9.33^{*} \pm 2.380$ \\
\hline$\geq 11$ & $25(24.75)$ & $14.00 \pm 5.172$ & $32.80 \pm 6.185$ & $17.44 \pm 8.109$ & $10.56^{*} \pm 2.694$ \\
\hline \multicolumn{6}{|l|}{ Attached to college } \\
\hline Yes & $76(75.25)$ & $13.62 \pm 4.421$ & $31.89 \pm 5.245$ & $17.63^{*} \pm 8.101$ & $9.71 \pm 2.627$ \\
\hline No & $25(24.75)$ & $13.92 \pm 3.581$ & $31.68 \pm 4.269$ & $13.56^{*} \pm 5.701$ & $9.40 \pm 2.121$ \\
\hline Total & & $13.69 \pm 4.214$ & $31.84 \pm 5.001$ & $16.62 \pm 7.755$ & $9.63 \pm 2.505$ \\
\hline Percentage & & 52.65 & 79.60 & 41.55 & 64.20 \\
\hline
\end{tabular}

*Significant at $5 \%$ level of significance, SD: Standard deviation; BDS: Bachelor of dental surgery; MDS: Master of dental surgery 
Table 2: Distribution of study subjects regarding willingness to participate, previous training, and familiarity with national document regarding disaster management

\begin{tabular}{lll}
\hline & Yes & No \\
\cline { 2 - 3 } Question & $n(\%)$ & $n(\%)$ \\
\hline $\begin{array}{l}\text { Willingness to participate in disaster } \\
\text { management }\end{array}$ & $97(96.04)$ & $4(3.96)$ \\
$\begin{array}{l}\text { Previous training on disaster } \\
\text { management }\end{array}$ & $5(4.95)$ & $96(95.05)$ \\
$\begin{array}{l}\text { Familiarity with "SOP for responding } \\
\text { to natural disasters, 2010" }\end{array}$ & $11(10.89)$ & $90(89.11)$ \\
\hline
\end{tabular}

Respondents belonging to Hindu religion reported higher attitude scores than those belonging to other religions ( $\mathrm{p}=0.042$, confidence interval [CI]: 0.09-4.60). Respondents with $\geq 11$ years of practice had higher perceived effectiveness scores than those with $\leq 10$ years of practice ( $\mathrm{p}=0.032, \mathrm{CI}:-2.36$ to -0.11$)$. Study subjects attached to private dental institution had higher behavior scores than those who were not attached to a private dental institutions ( $p=0.022$, CI: 0.60-7.54; Table 1).

A majority of 97 study subjects $(96.04 \%)$ reported positively for willingness to participate in managing disasters, while only 4 respondents $(3.96 \%)$ reported in the negative regarding the same. Only 5 respondents reported earlier training on managing disasters, while a vast majority of 96 respondents (95.05\%) had no previous training. Similarly, a majority of 90 study subjects $(89.11 \%)$ reported that they were not familiar with the Government of India's SOP for responding to natural disasters, 2010, whereas 11 respondents $(10.89 \%)$ reported familiarity with the document. Participants who strongly agreed that they can appropriately respond to disasters were $27.91 \%(n=24$; Table 2$)$.
It can be observed that there was statistically significant correlation between knowledge and attitude $(r=0.25$, $\mathrm{p}=0.01)$, knowledge and behavior $(\mathrm{r}=0.30, \mathrm{p}=0.00)$, attitude and perceived effectiveness $(r=0.21, \mathrm{p}=0.04)$, and behavior and perceived effectiveness $(\mathrm{r}=0.47, \mathrm{p}=$ 0.00 ; Table 3). Statistically significant correlations were also observed between religion and attitude $(r=-0.20$, $p=0.04)$, years of practice and perceived effectiveness $(\mathrm{r}=0.21, \mathrm{p}=0.03)$, and working in a dental institution and behavior of respondents toward disaster management $(\mathrm{r}=-0.23, \mathrm{p}=0.02 ;$ Table 4$)$.

Results of multiple linear regression analysis indicated that age $(\mathrm{OR}=0.609, \mathrm{p}=0.025)$, attitude $(\mathrm{OR}=$ $0.257, \mathrm{p}=0.009)$, and behavior $(\mathrm{OR}=0.367, \mathrm{p}=0.003)$ scores emerged as significant predictors of knowledge scores among respondents, while knowledge emerged as significant predictor of attitude scores $(\mathrm{OR}=0.288, \mathrm{p}=$ $0.009)$. It can also be observed that religion $(\mathrm{OR}=-0.194$, $\mathrm{p}=0.022)$, marital status $(\mathrm{OR}=-0.222, \mathrm{p}=0.040)$, attachment to college ( $\mathrm{OR}=-0.256, \mathrm{p}=0.037)$, familiarity with SOP $(\mathrm{OR}=-0.502, \mathrm{p}=0.000)$, and knowledge scores (OR $=0.265, p=0.003$ ) were significant predictors of behavior among study subjects. Results also indicate that years of experience $(\mathrm{OR}=0.529, \mathrm{p}=0.022)$, familiarity with SOP $(\mathrm{OR}=-0.431, \mathrm{p}=0.002)$, and behavior scores $(\mathrm{OR}=$ $0.290, p=0.012$ ) were significant predictors of perceived effectiveness (Table 5).

\section{DISCUSSION}

Obtaining insights into various issues related to public health emergencies among Indian GDPs was the primary objective of the investigators. Literature exploring these

Table 3: Correlation analysis of knowledge, attitude, and behavior among study subjects using Pearson correlation

\begin{tabular}{|c|c|c|c|c|c|c|c|c|}
\hline & \multicolumn{2}{|c|}{ Knowledge } & \multicolumn{2}{|c|}{ Attitude } & \multicolumn{2}{|c|}{ Behavior } & \multicolumn{2}{|c|}{ Perceived effectiveness } \\
\hline & $r$ & $p$ & $r$ & $p$ & $r$ & $p$ & $r$ & $p$ \\
\hline Knowledge & - & - & & & & & & \\
\hline Attitude & 0.250 & $0.012^{*}$ & - & - & & & & \\
\hline Behavior & 0.298 & $0.002^{* *}$ & 0.069 & 0.494 & - & - & & \\
\hline Perceived effectiveness & 0.179 & 0.074 & 0.207 & $0.038^{*}$ & 0.473 & $0.000^{* *}$ & - & - \\
\hline
\end{tabular}

*Significant at $5 \%$ level of significance; **Significant at $1 \%$ level of significance

Table 4: Correlation analysis of demographic variables with knowledge, attitude, and behavior about disaster management among study subjects

\begin{tabular}{|c|c|c|c|c|c|c|c|c|}
\hline \multirow{2}{*}{$\begin{array}{l}\text { Demographic } \\
\text { variables }\end{array}$} & \multicolumn{2}{|c|}{ Knowledge } & \multicolumn{2}{|c|}{ Attitude } & \multicolumn{2}{|c|}{ Behavior } & \multicolumn{2}{|c|}{ Perceived effectiveness } \\
\hline & $r$ & $p$ & $r$ & $p$ & $r$ & $p$ & $r$ & $p$ \\
\hline Age & 0.132 & 0.190 & 0.149 & 0.136 & -0.013 & 0.901 & 0.085 & 0.396 \\
\hline Gender & -0.044 & 0.663 & -0.065 & 0.516 & 0.095 & 0.344 & 0.100 & 0.319 \\
\hline Religion & -0.100 & 0.318 & -0.203 & $0.042^{*}$ & -0.124 & 0.218 & -0.155 & 0.122 \\
\hline Marital status & -0.108 & 0.283 & 0.095 & 0.345 & -0.111 & 0.270 & 0.032 & 0.754 \\
\hline Qualification & -0.047 & 0.640 & 0.127 & 0.205 & 0.092 & 0.361 & 0.099 & 0.324 \\
\hline Years of practice & 0.042 & 0.677 & 0.110 & 0.272 & 0.061 & 0.547 & 0.213 & $0.032^{*}$ \\
\hline Attached to college & 0.031 & 0.758 & -0.019 & 0.853 & -0.228 & $0.022^{*}$ & -0.054 & 0.593 \\
\hline
\end{tabular}

*Significant at $5 \%$ level of significance 
Table 5: Multiple linear regression analysis of various variables related to disaster management

\begin{tabular}{|c|c|c|c|c|c|}
\hline \multirow[b]{2}{*}{ Dependent variables } & \multirow[b]{2}{*}{ Independent variables } & \multirow[b]{2}{*}{ OR } & \multicolumn{2}{|c|}{$95 \% \mathrm{Cl}$ for OR } & \multirow[b]{2}{*}{$p$-value } \\
\hline & & & Lower & Upper & \\
\hline \multirow[t]{3}{*}{ Knowledge } & Age & 0.609 & 0.037 & 0.525 & $0.025^{*}$ \\
\hline & Attitude & 0.257 & 0.054 & 0.379 & $0.009^{* *}$ \\
\hline & Behavior & 0.367 & 0.071 & 0.328 & $0.003^{* *}$ \\
\hline Attitude & Knowledge & 0.288 & 0.086 & 0.598 & $0.009^{* *}$ \\
\hline \multirow[t]{5}{*}{ Behavior } & Religion & -0.194 & -3.413 & -0.273 & $0.022^{*}$ \\
\hline & Marital status & -0.222 & -7.654 & -0.186 & $0.040^{*}$ \\
\hline & Attached to college & -0.256 & -8.875 & -0.278 & $0.037^{*}$ \\
\hline & Familiarity with SOP & -0.502 & -17.970 & -6.883 & $0.000^{* * *}$ \\
\hline & Knowledge & 0.265 & 0.173 & 0.802 & $0.003^{* *}$ \\
\hline \multirow[t]{3}{*}{ Perceived effectiveness } & Years of practice & 0.529 & 0.024 & 0.298 & $0.022^{*}$ \\
\hline & Familiarity with SOP & -0.431 & -5.546 & -1.354 & $0.002^{* *}$ \\
\hline & Behavior & 0.290 & 0.021 & 0.166 & $0.012^{*}$ \\
\hline
\end{tabular}

*Significant at $5 \%$ level of significance; **Significant at $1 \%$ level of significance; ${ }^{* *}$ Significant at $0.1 \%$ level of significance

issues among GDPs is scarce. This investigation is the first study to report GDPs' potential role in managing public health emergencies in a highly disaster-prone region in India. It highlights the policy implications for health care delivery system and adapting multidisciplinary approach to effectively tackle emerging public health issues.

Dentists initially contributed toward mitigation of disasters as experts in forensic odontology and as members of military and "Disaster Mortuary Operational Response Teams" ${ }^{14,16}$ Dentists' contributions in managing natural calamities, such as tsunamis ${ }^{33-40}$ and earthquakes ${ }^{41,42}$; in accidents involving airplanes ${ }^{43-45}$ trains, ${ }^{46}$ ships,${ }^{47,48}$ and burns ${ }^{49}$; identification of unidentified bodies ${ }^{50}$ and human remains ${ }^{51}$; and dealing with mass suicides ${ }^{52}$ and mass graves, ${ }^{53,54}$ homicides, ${ }^{55}$ and terrorist attacks ${ }^{40}$ have been documented. Kieser et $\mathrm{al}^{33}$ have documented employability of dental records for the identification of tsunami victims in South Asia, while Wang et $\mathrm{al}^{41}$ have reported treatment of orofacial injuries among Chinese earthquake victims by oral and maxillofacial surgeons. With the advent of recent technological advancements, dental professionals' potential to contribute to disaster management was highlighted by Kieser et al. ${ }^{56}$

Chhabra et $\mathrm{al}^{24}$ have described certain issues pertinent to disaster management among GDPs in Rajasthan. Mangaluru is a city located in the Western Ghats of South India and might have different vulnerability and disaster management and mitigation issues compared with the dry and arid regions of Rajasthan. The questionnaire employed in the present study was tailor-made to reflect the same in the present study. Mangaluru also has a total of five dental colleges and seven medical colleges along with over 100 GDPs. Therefore, the disaster management scenario is considerably different from that in Rajasthan.

Respondents in this study had low knowledge scores, which are similar to the observations of Katz et $\mathrm{al}^{21}$ and Rajesh et al ${ }^{30,31}$ but do not concur with those observed by
Colvard et al. ${ }^{57}$ Low perceived effectiveness scores were observed in the present study, which are similar to that observed by Katz et $\mathrm{al}^{21}$ and Rajesh et al. ${ }^{30,31}$ This might be due to the absence of any specific training initiatives for Indian GDPs in mitigation of disasters. ${ }^{30,31}$ The respondents in the present study also reported higher attitude scores, which might indicate that they were interested in contributing effectively toward disaster management. Countries, such as the United States have taken definite strides in the process of integrating dentists in disaster management at various levels. This should serve as a useful indicator to decision-makers and policymakers in developing countries, such as India regarding the potential role that dentists can play in disaster management.

Respondents belonging to Hindu religion had higher attitude scores than those belonging to the other religions. These findings have to be confirmed by further explorations on the probable role of background factors in disaster management. Study subjects having experience of $\geq 11$ years had higher perceived effectiveness scores than those who were less experienced. With increasing work experience, respondents might feel more confident in handling patients who need more complex treatment procedures, and this might be reflected in their perceived effectiveness. The GDPs attached to a dental institution reported higher behavior scores than those who were not attached to dental institution. Access to scientific literature, such as journals and articles, recent textbooks, exposure to continuing dental education, or continuing professional development programs in dental institutions might have led to higher behavior scores among respondents.

Results indicate that knowledge scores and attachment to dental college emerged as significant predictors of behavior scores. Knowledge forms the foundation, which might positively influence the behavior of respondents. Attachment to dental college might provide various avenues to update oneself with recent developments, 
which might have had a positive influence on the behavior of respondents. Years of practice and behavior scores were significantly associated with the perceived effectiveness of respondents. As the experience increases, this might have a cumulative impact on the perceived effectiveness of the respondents. Higher behavior scores related to disaster management might enhance the perceived effectiveness of the participants.

Biases inherent with the use of questionnaires, such as yea-saying/acquiescence bias, social desirability, or faking good/bad (social desirability/deviation) biases will have to be considered. Use of Likert scales might involve the halo effect, positive skew, and end-aversion bias. ${ }^{32}$ Further research needs to be undertaken to fully understand the aforementioned aspects.

The necessity of involving and integrating medical and other health care personnel for handling disasters is imperative. ${ }^{4,5}$ Coordinated efforts across different health professionals and different communities and agencies in different geographical localities, i.e., implementation of a multidisciplinary approach, is critical for effective disaster management. Including GDPs might be a step toward these combined coordinated efforts. This is particularly relevant to developing nations, such as India that face the dual issues of enhanced susceptibility to calamities and few resources. Bremer ${ }^{25}$ has observed that medical intelligence and sociogeographical mapping are essential elements of disaster management. The GDPs need little further training to be a part of the team that efficiently mitigates disasters. Chhabra ${ }^{26}$ has also highlighted the importance of building networks among different experts, communities, and countries to tackle various aspects of disaster management.

There are definite policy implications pertaining to training and curriculum development/modifications for health care professionals in India. The need for incorporation of competencies for disaster management at undergraduate training has been highlighted. ${ }^{58,59}$ This will enable dental professionals to be involved not only in disaster response but also in surveillance activities. Investigators have also highlighted the importance of dental professionals continuously familiarizing with scientific literature related to disaster management. ${ }^{60}$

The importance of including aspects related to mitigation of disasters in the undergraduate dental curriculum has been highlighted. ${ }^{13,58}$ Attempts to undertake such endeavors have been reported in scientific literature. ${ }^{4,5,58,61}$ The topics that the Dental Council of India ${ }^{62}$ prescribes for undergraduate dental education in India might be of significant relevance to disaster management. Various aspects in microbiology, pharmacology, general medicine, general and oral and maxillofacial surgery, oral and maxillofacial radiology, and Public Health Dentistry might have a special bearing on disaster management. Investigators have also reported that the prescribed disaster management competencies are already a part of the curriculum in dental undergraduate training. 5,56 One can consider refining certain aspects of curriculum to lay more emphasis on disaster management at the undergraduate level. Financial aspects of additional undergraduate training and administrative aspects of including additional training in a curriculum which is already tightly scheduled should be considered in the context of curriculum changes. ${ }^{58}$

Regular training programs for GDPs on disaster management might be a crucial aspect. Training programs similar to those currently being implemented in courses pertaining to basic and advanced life support should be considered for disaster management. Simon and Teperman ${ }^{63}$ have stressed the need for developing credentialing systems for physicians and nurses for better responses during disasters. However, the shortcomings of such changes also need to be borne in mind. Tong ${ }^{64}$ has observed that dentists might have to change their mindset so as to effectively perform in an area that is outside their normal practice. Dentists working in individual private practices might also have to adapt to working together in the team.

Undertaking training initiatives for individuals from different backgrounds during multidisciplinary endeavors might be challenging. Different baseline skill sets, diverse cultural backgrounds, dissimilar previous training experiences and work profiles, and financial aspects of additional training might pose special problems. . $^{59,65}$ Clear definition of target audience should be undertaken, and rendering tailor-made training for this target audience should be attempted. Besides, one has to consider the potential legal ramifications of involving GDPs in specific procedures during disasters. ${ }^{14,19,64}$ Kaur $^{66}$ has also highlighted the administrative issues that might arise in the wake of disasters in India. These crucial issues that might impede capacity building in managing disasters should be addressed.

Public health emergencies are a discipline that is constantly evolving by the day. One has to consider the new emerging infectious diseases and its potential implications on disaster management. ${ }^{67}$ Identification of best practices pertaining to disaster management ${ }^{65}$ and implementing evidence-based approach in disaster management ${ }^{68,69}$ are the need of the hour. One of the important aspects of research on disaster management in developing countries has been highlighted by Roy et al. ${ }^{70}$ They have observed that the amount of literature being reported from developing countries is not commensurate with the number of disaster occurring in these regions. Further research from areas highly afflicted by disasters 
needs to be conducted and reported to add to the evidence base pertaining to disaster management.

Investigators have observed that only minimal training was required for dentists who had undergone training under the National Disaster Life Support curriculum of the American Medical Association. ${ }^{56}$ This indicates that dentists can be effectively and meaningfully incorporated into disaster management activities. Lessons gleamed from such exercises might have special relevance to India and other developing nations which have few resources, but which are highly vulnerable to disasters. Involving clinicians might have critical implications for effective disaster management. ${ }^{71}$ One also has to consider the involvement of other health care professionals, such as nurses, pharmacists, and physiotherapists to render disaster management more effective.

Comfort ${ }^{72}$ has observed that with the rate and manner in which populations are growing, shaping, and behaving, the risk of development of disaster is only increasing. This increasing frequency of disasters, especially in developing countries like India, is a major public health problem. Huge number of GDPs possessing skills that can aid in mitigating disasters in a nation with low resources calls for integration of various sectors for effectively handling public health emergencies. The present study highlights the curriculum and training implications for dental professionals in India.

\section{CONCLUSION}

Willingness to participate in mitigating disasters and attitude scores were high among Indian GDPs. However, low knowledge and behavior scores were observed. Respondents with experience $\geq 11$ years had higher perceived effectiveness scores than those with lesser experience. Respondents attached to dental institutions had higher behavior scores than those who were not attached. Knowledge was significantly associated with attitude and behavior scores, whereas attitude and behavior were significantly associated with perceived effectiveness scores. Religion of respondents showed significant correlation with attitude, whereas years of experience showed significant correlation with perceived effectiveness. Attachment to a dental institution was significantly associated with behavior of the study subjects. Religion, marital status, attachment to college, familiarity with SOP, and knowledge scores emerged as significant predictors of behavior among study subjects.

\section{CLINICAL SIGNIFICANCE}

Integrating various health care professionals and adopting a multidisciplinary approach need to be considered earnestly. This approach, especially, is relevant in highly disaster-prone countries like India. The present study highlights the potential role that GDPs can play in effective and efficient disaster management in India. Policy changes pertaining to health care delivery system and curriculum and training to effectively deal with public health emergencies are the need of the hour.

\section{ACKNOWLEDGMENT}

Authors would like to thank Dr Shuba Kumar, social scientist, SAMARTH, Chennai, India, for being a source of inspiration.

\section{REFERENCES}

1. Balakrishnan, BA. Disaster management in India. 2009. [cited 2016 Aug 9]. Available from: http:/ /www.ndc.nic.in/ research_papers/Paper-3_ndc_2009.pdf.

2. Shapira SC, Shemer J. Medical management of terrorist attacks. Isr Med Assoc J 2002 Jul;4(7):489-492.

3. Sen A, Chander M. Disaster management in India: the case of livestock and poultry. Rev Sci Tech 2003 Dec;22(3):915-930.

4. More FG, Phelan J, Boylan R, Glotzer D, Psoter W, Robbins M, Rekow ED, Alfano MC. Predoctoral dental school curriculum for catastrophe preparedness. J Dent Educ 2004 Aug;68(8): 851-858.

5. Psoter WJ, Herman NG, More FG, Park P, Robbins M, Rekow ED, Ryan JM, Triola MM, Glotzer D. Proposed educational objectives for hospital-based dentists during catastrophic events and disaster response. J Dent Educ 2006 Aug;70(8):835-843.

6. Glotzer DL, Rinchiuso A, Rekow ED, Triola MM, Psoter WJ. The medical reserve Corps. an opportunity for dentists to serve. N Y State Dent J 2006 Jan;72(1):60-61.

7. Gupta, A. The great Gujarat earthquake 2001-lessons learnt. In: Proceedings of 22nd Asian Conference on Remote Sensing, 5-9 November, 2001, Singapore. Centre for Remote Imaging, Sensing and Processing (CRISP) of the National University of Singapore, Singapore Institute of Surveyors and Valuers (SISV). Singapore: Asian Association on Remote Sensing (AARS); 2001. p. 306-309.

8. O'Neill PA. The ABC's of disaster response. Scand J Surg 2005 Dec;94(4):259-266.

9. Becker SM. Psychosocial care for adult and child survivors of the 2004 tsunami disaster in India. Am J Public Health 2006 Aug;96(8):1397-1398.

10. Bhave SY, Choudhury P, Pemde HK, Mathur YC, IAP Task Force on Child at Risk. IAP workshop on disaster management practices: recommendations and IAP plan of action. Indian Pediatr 2005 Sep;42(9):887-903.

11. Colvard MD, Lampiris LN, Cordell GA, James J, Guay A, Lee M, Stokes CM, Scott G. The dental emergency responder: expanding the scope of dental practice. J Am Dent Assoc 2006 Apr;137(4):468-473.

12. Vale GL, Noguchi TT. The role of the forensic dentist in mass disaster. Dent Clin N Am 1977 Jan;21(1):123-135.

13. Guay AH. Dentistry's response to bioterrorism: a report of a consensus workshop. J Am Dent Assoc 2002 Sep;133(9): 1181-1187.

14. Galligan JM. Dentists can contribute expertise in a major public health disaster. J Calif Dent Assoc 2004 Aug;32(8):701-708. 
15. Flores S, Mills SE, Shackelford L. Dentistry and bioterrorism. Dent Clin North Am 2003 Oct;47(4):733-744.

16. Chandra Shekar BR, Reddy CV. Role of dentist in person identification. Indian J Dent Res 2009 Jul-Sep;20(3):356-360.

17. Psoter WJ, Park PJ, Boylan RJ, Morse DE, Glotzer DL. National emergency response programs for dental health care professionals. J Am Dent Assoc 2008 Aug;139(8):1067-1073.

18. Jeffcoat MK. Are we ready? Thinking about the unthinkable. J Am Dent Assoc 2002 Dec;133(12):1600-1604.

19. Rekow ED. The dental team: a ready reserve or an overlooked resource? J Am Dent Assoc 2006 Apr;137(4):432-434.

20. Glick M. Vaccines, epidemics, pandemics and us. J Am Dent Assoc 2006 Jun;137(6):706-710.

21. Katz AR, Nekorchuk DM, Holck PS, Hendrickson LA, Imrie AA, Effler PV. Dentists' preparedness for responding to bioterrorism: a survey of Hawaii dentists. J Am Dent Assoc 2006 Apr;137(4):461-467.

22. Guay AH. The role dentists can play in mass casualty and disaster events. Dent Clin North Am 2007 Oct;51(4):767-778.

23. Glick M. When pigs fly. Confronting the new era of disease transmission. J Am Dent Assoc 2005 Mar;136(3):270-274.

24. Chhabra KG, Rajesh G, Chhabra C, Binnal A, Sharma A, Pachori Y. Disaster management and general dental practitioners in India: an overlooked resource. Prehosp Disaster Med 2015 Dec;30(6):569-573.

25. Bremer R. Policy development in disaster preparedness and management: lessons learned from the January 2001 earthquake in Gujarat, India. Prehosp Disaster Med 2003 Oct-Dec;18(4):372-384.

26. Chhabra V. Connecting care competencies and culture during disasters. J Emerg Trauma Shock 2009 May;2(2):95-98.

27. Patil PH. Disaster management in India. Indian Streams Res J 2012 Feb;2(1):1-4.

28. Government of India. Disaster management in India-A status report. New Delhi: Ministry of Home Affairs, National Disaster Management Division; 2004.

29. Dental Council of India, Government of India. New Delhi: Dental Council of India; 2012. [cited 2012 Dec 7]. Available from: http:/ / www.dciindia.org.

30. Rajesh G, Chhabra KG, Shetty PJ, Prasad KV, Javali SB. A survey on disaster management among postgraduate students in a private dental institution in India. Am J Disaster Med 2011 Sep-Oct;6(5):309-318.

31. Rajesh G, Pai MB, Shenoy R, Priya H. Willingness to participate in disaster management among Indian dental graduates. Prehosp Disaster Med 2012 Oct;27(5):439-444.

32. Steiner, DL.; Norman, GR.; editors. Health measurement scales: a practical guide to their development and use, PDQ statistics. Oxford: Oxford University Press; 1995. p. 15-26.

33. Kieser JA, Laing W, Herbison P. Lessons learned from largescale comparative dental analysis following the South Asian tsunami of 2004. J Forensic Sci 2006 Jan;51(1):109-112.

34. De Valck E. Major incident response: collecting ante-mortem data. Forensic Sci Int 2006 May;159(Suppl 1):S15-S19.

35. Lessig R, GrundmannC,DahlmannF,EdelmannJ,SchneiderPM. Tsunami 2004-a review of one year of continuous forensic medical work for victim identification. EXCLI J 2006 Oct;:5:128-139.

36. Perrier M, Bollmann M, Girod A, Mangin P. Swiss DVI at the tsunami disaster: expect the unexpected. Forensic Sci Int 2006 May;159(Suppl 1):S30-S32.
37. Petju M, Suteerayongprasert A, Thongpud R, Hassiri K. Importance of dental records for victim identification following the Indian Ocean tsunami disaster in Thailand. Public Health 2007 Apr;121(4):251-257.

38. Schuller-Götzburg P, Suchanek J. Forensic odontologists successfully identify tsunami victims in Phuket, Thailand. Forensic Sci Int 2007 Sep;171(2-3):204-207.

39. Bajaj A. Disaster victim identification: tsunami. Br Dent J 2005 Apr;198(8):504-505.

40. Hinchliffe JA. Disaster dentistry. Br Dent J 2007 Apr;202(8): 493-494.

41. Wang L, Wei JH, He LS, Cao M, Cao J, Liu YP, Lei DL, Zhao YM. Dentists' role in treating facial injuries sustained in the 2008 earthquake in China: how dental professionals can contribute to emergency response. J Am Dent Assoc 2009 May;140(5):543-549.

42. Dai J, Zhao Y, Li G. Wenchuan earthquake: response of Chinese dental professionals. Br Dent J 2009 Mar;206(5):273-276.

43. Brannon RB, Morlang WM. Tenerife revisited: the critical role of dentistry. J Forensic Sci 2001 May;46(3):722-725.

44. Brannon RB, Morlang WM. The crash of LOT flight 007: dental identification. J Forensic Sci 2002 Nov;47(6):1323-1325.

45. Brannon RB, Morlang WM, Smith BC. The gander disaster: dental identification in a military tragedy. J Forensic Sci 2003 Nov;48(6):1331-1335.

46. Dumancic J, Kaic Z, Njemirovskij V, Brkic H, Zecevic D. Dental identification after two mass disasters in Croatia. Croat Med J 2001;42(6):657-662.

47. Brannon RB, Morlang WM. The USS Iowa disaster: success of the forensic dental team. J Forensic Sci 2004 Sep;49(5): 1067-1068.

48. Titley KC, Pynn BR, Chernecky R, Mayhall JT, Kulkarni GV, Ruffman A. The Titanic disaster: dentistry's role in the identification of an 'unknown child'. J Can Dent Assoc 2004 Jan;70(1):24-28.

49. Valenzuela A, Martin-de las Heras S, Marques T, Exposito N, Bohoyo JM. The application of dental methods of identification to human burn victims in a mass disaster. Int J Legal Med 2000 Jun;113(4):236-239.

50. Nedel F, Nedel AP, da Silva RH, Lund RG. Evaluation of identification cases involving forensic dentistry in the city of Pelotas, RS, Brazil, 2004-2006. Braz J Oral Sci 2009 Jan-Mar;8(1): 55-58.

51. Nuzzolese E, Liuzzi C, Quarta G, Calcagnile L, Di Vella G. Dental contribution to an anthropological forensic case work of skeletal remains in Miglionico Countryside (South Italy). Open Anthropol J 2010 Jul;3:142-147.

52. Brannon RB, Morlang WM. Jonestown tragedy revisited: the role of dentistry. J Forensic Sci 2002 Jan;47(1):3-7.

53. Djurić MP, Milenković PP, Djukić KM. Dental status of victims from Batajnica's mass graves. Coll Antropol 2009 Dec;33(4):1387-1395.

54. Djuric M, Dunjic D, Djonic D, Skinner M. Identification of victims from two mass-graves in Serbia: a critical evaluation of classical markers of identity. Forensic Sci Int 2007 Oct;172(2-3):125-129.

55. Pretty IA, Sweet D. A look at forensic dentistry-part 1: the role of teeth in the determination of human identity. Br Dent J 2001 Apr;190(7):359-366.

56. Kieser J, de Feijter J, TeMoananui R. Automated dental aging for child victims of disasters. Am J Disaster Med 2008 Mar-Apr;3(2):109-112. 
57. Colvard MD, Naiman MI, Mata D, Cordell GA, Lampiris L. Disaster medicine training survey results for dental health care providers in Illinois. J Am Dent Assoc 2007 Apr;138(4):519-524.

58. ChmarJE, Ranney RR, Guay AH, Karl Haden N, Valachovic RW. Incorporating bioterrorism training into dental education: report of ADA-ADEA terrorism and mass casualty curriculum development workshop. J Dent Educ 2004 Nov;68(11):1196-1199.

59. Supe A, Satoskar R. Health services responses to disasters in Mumbai sharing experiences. Indian J Med Sci 2008 Jun;62(6):242-251.

60. Frykberg ER. Principles of mass casualty management following terrorist disasters. Ann Surg 2004 Mar;239(3):319-321.

61. Glotzer DL, More FG, Phelan J, Boylan R, Psoter W, Robbins M, Rekow ED, Godder B, Alfano MC. Introducing a senior course on catastrophe preparedness into the dental school curriculum. J Dent Educ 2006 Mar;70(3):225-230.

62. Dental Council of India. Regulation for the Degree of Bachelor of Dental Surgery, The Gazette of India, extraordinary, part III, section 4, Dental Council of India Notification. New Delhi: Dental Council of India; 2007.

63. Simon R, Teperman S. The world trade center attack: lessons for disaster management. Crit Care 2001 Nov;5(6):318-320.
64. Tong MD. The role of dentists in a mass casualty situation: a New Zealand perspective. J Mil Veterans Health 2008;16(4):20-25.

65. Hsu EB, Thomas TL, Bass EB, Whyne D, Kelen GD, Green GB. Health care worker competencies for disaster training. BMC Med Educ 2006 Mar;6:19.

66. Kaur J. Administrative issues involved in disaster management in India. Int Rev Psychiatry 2006 Dec;18(6):553-557.

67. Hawryluck L, Lapinsky SE, Stewart TE. Clinical review: SARS-lessons in disaster management. Crit Care 2005 Aug;9(4):384-389.

68. Auf der Heide E. The importance of evidence-based disaster planning. Ann Emerg Med 2006 Jan;47(1):34-49.

69. Tharyan P, Clarke M, Green S. How the Cochrane collaboration is responding to the Asian tsunami. PLoS Med 2005 Jun;2(6):e169.

70. Roy N, Thakkar P, Shah H. Developing-world disaster research: present evidence and future priorities. Disaster Med Public Health Prep 2011 Jun;5(2):112-116.

71. Gerberding JL, Hughes JM, Koplan JP. Bioterrorism preparedness and response: clinicians and public health agencies as essential partners. JAMA 2002 Feb;287(7):898-900.

72. Comfort LK. Risk, security, and disaster management. Annu Rev Polit Sci 2005 Mar;8:335-356. 